\title{
Evolution of pain management services in Nepal
}

\author{
Anil Shrestha, Roshana Amatya, Ninadini Shrestha
}

1-Anil Shrestha, Associate Professor, Department of Anesthesiology, Tribhuvan University Teaching Hospital, Maharajgunj Medical Campus, Institute of Medicine, Kathmandu, Nepal.

2-Roshana Amatya, Professor, Department of Anesthesiology, Tribhuvan University Teaching Hospital, Maharajgunj Medical Campus, Institute of Medicine, Kathmandu, Nepal.

3-Ninadini Shrestha, Assistant Professor, Department of Anesthesiology, Tribhuvan University Teaching Hospital, Maharajgunj Medical Campus, Institute of Medicine, Kathmandu, Nepal.

Corresponding author: Dr. Anil Shrestha; Phone: +977- 9851069727; E-mail: aanilsh@hotmail.com

\begin{abstract}
Pain is one of the most common symptoms of patients visiting the hospital. The prevalence of chronic pain is estimated to be around $30 \%$. Pain management service is a separate service provided by healthcare institutions to manage such chronic pain and has become essential service in most of the countries. Nepal has also started to provide services for patients with chronic pain through pain management clinics. To start such a service in a resource-poor country like Nepal was not an easy task. It took a long time for the physicians, the society as well as the health authorities to realize the need to make such a service available in Nepal. The establishment of such pain clinics is gaining momentum and more qualified pain physicians are being produced now. This article describes briefly, the journey of developing pain management services in Nepal from infancy to maturity.
\end{abstract}

Key words: Nepal; Pain; Pain management; Pain clinic

Citation: Shrestha A, Amatya R, Shrestha N. Evolution of developing pain management services in Nepal. Anaesth. pain intensive care 2020;24(4):463-466.

Received: 9 January 2020, Reviewed: 18 February 2020, Accepted: 22 February 2020

\section{Introduction}

Pain is a very subjective and individual experience, making it very difficult to accurately define or measure it. Pain is one of the most common symptoms experienced at some point during the course of many illnesses. The impact of chronic pain, when it isn't protective and becomes a disease in itself, can have a significant effect on the lives of those affected. It is a heavy burden to our healthcare system, where chronic pain may also result in physical and psychological disability. ${ }^{1}$

The prevalence of chronic pain worldwide is estimated to be around $30 \%$, whereas in Kathmandu, the capital city of Nepal, a study showed its prevalence to be $50 \%$ along with some form of disability present. ${ }^{2}$ The findings suggest a greater prevalence of pain in this area. ${ }^{3}$ The work-days loss due to pain was 1.37 days/month/person and pain related losses in terms of Nepalese Rupees were $1671.89 /$ person/year according to one study done by Bhattarai B et al. ${ }^{4}$

It has been 54 years since the 1965 Science publication "Pain Mechanisms: A New Theory" by Ronald Melzack and Patrick D. Wall, in which the authors introduced the gate control theory of pain that has since revolutionized our understanding of pain mechanisms and management. ${ }^{5}$ Dr. John Bonica was the one to propose a multidisciplinary approach for the pain management. He was the key person in organizing the first international symposium on pain in Washington in May 1973. It was participated by the most of the leading pain advocates which led to the formation of IASP (International Association for the Study of Pain). After the success of the symposium, pain medicine got a great momentum for rapid growth as an individual specialty. Although the growth was slow in the early days, important milestone in pain 
management such as the proposal of theories to describe pain mechanism, discovery of various pharmacological drugs such as morphine and NSAIDs, introduction of a dedicated pain clinic, was achieved in this period. In 1978, Dr. John Bonica founded the first multidisciplinary pain center at the University of Washington. ${ }^{6}$ The typical management team included medical practitioners, clinical psychologists, physiotherapists, occupational therapists, physician assistants, nurses and the pharmacists. Dr. Prithvi Raj, Dr. Laxmaiah Manchikanti and Dr. Steven D. Waldman contributed a lot in the development of pain management services. The science of pain management has been rapidly developing since then in the western world.

\section{Pain management services in Nepal}

The documented evidence of the start of interventional pain management in Nepal is not known; however, Swar BB has mentioned about an American pain specialist coming to Nepal to provide epidural steroid injection to a princess in 1970s. ${ }^{7}$ The concept of pain management had since developed and the first pain clinic was established in 1985 in a private hospital initiated by Dr. B. B. Swar, who was an anesthesiologist. ${ }^{7} \mathrm{He}$ also started pain clinics in medical colleges, but this step could not get its due acceptance. Institution based pain management clinics were started in B P Koirala Institute of Health Sciences (BPKIHS), Dharan and Tribhuvan University Teaching Hospital (TUTH), Institute of Medicine Kathmandu, about two decade ago and are now being developed more and more. Initially we had a lot of limitations, e.g., lack of skilled human resources, lack of proper infrastructure, lack of realization of the importance of pain clinics by the hospital authorities. To strengthen the service, technical skills and knowledge, pain specialists Dr Mark Churcher from UK, Prof Dennid Reid from Canada and Prof GP Dureja from AIIMS, India helped us a lot during these initial phases.

Anesthesiologists from Nepal also developed interest in pain management services. The trend of getting training in pain management or attending pain related events also started. BPKIHS organized first 'International Conference on Pain' in February 2000, which was attended by more than 200 delegates from around the world.8 This event served as a great encouragement to Nepalese anesthesiologists.

A workshop was organized on hands-on regional anesthesia in collaboration with MD Anderson Cancer Centre Texas in 2007 AD during the conference of South Asian Confederation of Anesthesiologists. This workshop helped Nepalese anesthesiologists to upgrade their knowledge about nerve blocks. In 2011 a symposium on live demonstration of radiofrequency lesioning in interventional pain management was organized in TU Teaching Hospital in collaboration with Varanasi Hindu University by Prof V. Rastogi (Figure 1).

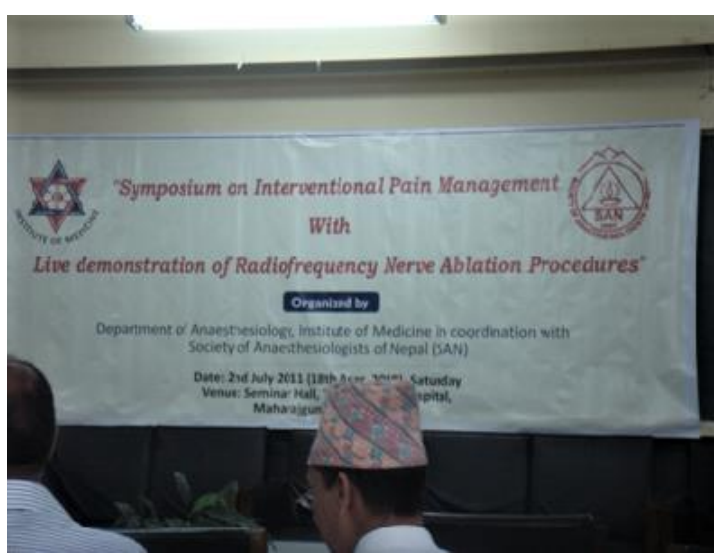

Figure 1: Clip from symposium on interventional pain management at T U Teaching Hospital in 2011

Besides this, training in interventional pain management and palliative care was started for the faculties at different institutions, such as three months observership in MD Anderson Cancer Centre, USA in 2006 and one month hands-on training in pain management at AIIMS, New Delhi and Varanasi Hindu University India. It was only since 2011 AD when young doctors interested in pain management started to have formal fellowship training in pain management. Since then there are two to three young doctors getting fellowship trainings in pain management every year from different countries joining the pain fraternity in Nepal. Gradually with the dedication and determination of the faculties, institution based pain management clinics have been providing outpatient services as well as interventions as per need regularly. Common interventions being done include trigeminal nerve blocks, epidural steroid injections, trigger point injection, chemical lumbar 
sympathectomy, and celiac plexus blocks under fluoroscopy.

\section{Current scenario}

The current scenario is very progressive and aspiring. The establishment of Nepal Association for the Study of Pain (NASP) on 8th January 2017 and its acceptance by International Association for the Study of Pain (IASP) as its Nepal chapter in 2018, has now seeded the future of a more comprehensive care for Nepalese people suffering from chronic pain. NASP emphasizes more on the importance of individualized patient-centered care in the diagnosis and treatment of acute and chronic pain. IASP together with World federation of societies of anesthesiologist (WFSA) have been providing fellowship trainings to young anesthesiologist of developing countries and many anesthesiologists from Nepal have also been trained by such fellowship programs. To further develop the field of pain management NASP is regularly conducting continued medical educations and different workshops in Nepal. NASP has also been incorporated in South Asian regional pain society (SARPS).

Perioperative pain and acute pain associated with trauma or burns etc. are nowadays treated with a multimodal approach, which includes medications, nerve blocks, physical therapy and other modalities as needed. A multidisciplinary approach for chronic pain across various disciplines, using one or more treatment modalities is emerging as a common practice. Pain is an integrative sum of nociceptive input combined with multiple factors that modulate this input to generate the complex and individual experience of pain, producing multidimensional aspects of pain. Thus, management of pain also differs from patient to patient even for the same problem, which demands precise individual care, making it very challenging for the team involved to come up with guidelines or protocols. So, pain management teams in Nepal comprise of many subject experts like anesthesiologists, pain specialists, neurologists, neurosurgeons, orthopedicians, psychologists, physiatrists, physical medicine and rehabilitation specialists, and physiotherapists etc. A multidisciplinary multimodal approach with assessment and treatment can produce best results for the severe persistent problems.
Various classes of medications, including non-opioids and opioids are available in Nepal now. The prescription is mostly based on the etiologic diagnosis, the mechanism of pain, and related co-morbidities following a thorough history and physical examination. The Nepalese drug companies licensed to produce analgesics, ranging from NSAIDs to opioids and adjuvant medicines, has made the availability of drugs more sustainable. The insurgence of opioid crisis has influenced opioid drug regulations making it a pain crisis as well. Ensuring safe medication storage is however still a challenge to ensure best clinical outcomes. Restorative therapy implemented by physical therapists and occupational therapists are valuable components of healthcare in Nepal. Many interventional approaches, including image-guided and minimally invasive procedures, are

Events in development of pain services in
Nepal:
1970 s - First known pain service in Nepal by
a foreign doctor
1985 - First pain clinic established in Nepal
2000 - First international conference on pain
organized in Nepal
2004 - Institution based pain service started in
Nepal
2011 - Physicians with fellowship in pain
management degrees
2017 - Establishment of NASP
$\mathbf{2 0 1 8}$-NASP recognized by IASP as a
country chapter

available as diagnostic and therapeutic treatment modalities for acute and chronic pain when clinically indicated. A range of various types of procedures, including trigger point injections, nerve blocks, hydrodissection, regenerative medicine, radiofrequency ablation, neuromodulation, and other procedures are readily available. Behavioral approaches for psychological, cognitive, emotional, behavioral, and social aspects of pain are commonly practiced by psychiatrists and psychologists, which can have a significant impact on treatment outcomes. Treatment modalities such as acupuncture, massage, movement therapies (e.g., yoga, exercise), and spirituality, are considered when clinically indicated. 
Effective multidisciplinary management to treat complex aspects of acute and chronic pain cannot be achieved without taking biopsychosocial aspect of human nature into consideration. There are still limitations with all services being available but gradually there is an increasing number of professionals who are pursuing this as a career, as the people have started to realize that quality care is almost impossible without adequate attention to pain management.

Nepal is very diverse geographically, as well as culturally, which predisposes the Nepalese people to a variety of chronic painful conditions. The lifestyle they adopt in very hurtful environments exposes them to excessive wear and tear of their body parts. It is thought that many of those conditions are preventable and are mostly the result of neglect and lack of awareness about healthcare.

Our population has very limited access to information as well as service of specialist pain services in Nepal as many health workers themselves are unaware of the possibilities these services can provide. We need to develop sustainable plans to improve education, awareness and services to diverse area of Nepal which can happen with incorporation of education about Pain management in the health policy of the country. Constant efforts of pain education by workshops like essential pain management (EPM) to health workers in all provinces of Nepal since 2012, has laid the foundation of prioritizing pain management as an important part of quality healthcare. Pain management service is now extended to many major cities in Nepal with more and more healthcare providers specializing in this specialty. Curriculum of masters degree in anesthesiology of different university and institutes of Nepal have also incorporated pain management clinics as an essential requirement criteria for medical colleges to be eligible to start the program. It has also enabled us to develop pain services in Nepal.

\section{Conclusion}

We have been very hopeful for further development of pain management services in a more integrated way under the umbrella of NASP and will be working in close coordination with other IASP Chapter societies in our neighboring countries. Hopefully in near future we will have many dedicated pain management centers with better assessment facilities, better equipment and monitoring facilities, offering all needed pain management related services under the same roof. Pain management and the pain practitioners have a bright and secure future in Nepal.

\section{Conflict of interest}

None declared by the authors

\section{Authors' contribution}

AS: Concept, Literature review, manuscript preparation, Manuscript review and editing

RA: Concept, manuscript review, manuscript editing

NS: Literature review, manuscript preparation, Manuscript editing

\section{References}

1. Poole H, White S, Blake C, Murphy P, Bramwell R. Depression in chronic pain patients: prevalence and measurement. Pain Pract. 2009;9(3):173-180. [PubMed] DOI: 10.1111/j.1533-2500.2009.00274.x

2. Walters JL, Baxter $\mathrm{K}$, Chapman $\mathrm{H}$, Jackson $\mathrm{T}$, Sethuramachandran A, Couldridge $M$, et al. Chronic pain and associated factors in India and Nepal: A pilot study of the Vanderbilt Global Pain Survey. Anesth Analg. 2017 Nov;125(5):1616-1626. [PubMed] DOI: 10.1213/ANE.0000000000002360

3. Baxter K. Pain in Nepal: Analysis of prevalence, impact and treatment in the Kathmandu District. Anesth Analg. 2016;123(3S):367.

DOI: 10.1213/01.ane.0000492681.99400.53

4. Bhattarai B, Pokharel PK, Tripathi M, Rehman TR, Baral $D D$, Pande $R$, et al. Chronic pain and cost: An epidemiological study in the communities of Sunsari district of Nepal. Nepal Med Coll J. 2007;9(1):6-11 [PubMed]

5. Melzack R, Wall PD. Pain mechanisms: A new theory. Science. 1965;150:971-979. [PubMed] DOI: 10.1126/science. 150.3699 .971

6. Liebeskind JC. In remembrance of John and Emma Bonica. Pain. 1994;59(3):425. DOI: 10.1016/03043959(94)90032-9

7. Swar B.B. Pain practice in Nepal thirty years ago: A practitioner's Quest. JSAN. 2017;4(2):49-53. DOI: 10.3126/jsan.v4i2.21203

8. Bhattarai B. Establishing pain service in Dharan Nepal: overcoming the inertia. JSAN. 2019;6(1). DOI: 10.3126/isan.v6i1.24099 